REVISTA CRIOULA N ${ }^{\circ} 20-2^{\circ}$ SEMESTRE $/ 2017$

\title{
Memórias dA “MANIDADE NEGRA" DENTRO DA LUTA POR UMA EDUCAÇÃO DEMOCRÁTICA
}

\section{MeMORIES OF THE "BLACK SISTERHOOD” WITHIN THE STRUGgLE} FOR A DEMOCRATIC CULTURE

Louise Marinho e Milena Natividade da Cruz

DOI: 10.11606/issn.1981-7169.crioula.2017.139882

\section{Resumo}

A escrita dessa memória surgiu da necessidade subjetiva, psíquica e política de elaborarmos a nossa vivência no Cursinho da Psicologia - USP enquanto educadoras negras, principalmente após tencionarmos a "experiência segura" de educação que se pretende popular, trazendo para o centro das discussões educacionais a questão racial, que, até então, era tratada como temática concernente apenas a uma disciplina da grade educacional, o C.R.I.S.E. (Coletivo de Reflexão e Intervenção sobre o Espaço). A natureza dessa escrita, uma "autorreflexão compartilhada", nos permitiu interseccionar, na nossa experiência docente, as questões identitárias que nos compõem. Esse exercício narrativo não segue o caminho de nos descobrirmos enquanto "mulheres - professoras - negras", mas sim de elaborarmos como produzimos, simultaneamente, a nós e as nossas estratégias pedagógicas, bem como a nossa relação com o corpo docente e discente. 


\section{Abstract}

The writing of this memory arose from the subjective, psychic and political necessity of elaborating our experience at Cursinho da Psicologia - USP while being black educators, especially after the "safe experience" of popular education. We bring to the center of educational discussions the racial question, which until then was treated as a theme related to only one subject of the educational program, the C.R.I.S.E. (Coletivo de Reflexão e Intervenção sobre o Espaço) [Collective for Reflection and Intervention on Space]. The nature of this writing, a "shared self-reflection", allowed us to intersect in our teaching experience the identity issues that form us. This narrative exercise does not follow the path of discovering ourselves as "women - teachers - black women", but rather of elaborating how we simultaneously produce ourselves and our pedagogical strategies, as well as our relationship with the teachers and students.

\section{Nosso hISTÓRICO E dO COLETIVO}

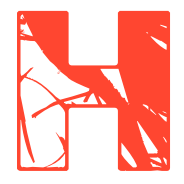

á cerca de dois anos, decidimos compor o Cursinho da Psicologia - USP, um coletivo de formação docente voltado à educação popular e que tem como missão desenvolver uma política educacional democrática no contexto dos cursinhos pré-vestibular na Universidade de São Paulo. Criado na década de 90 , o projeto tem sido modificado ao longo desse tempo a fim de proporcionar, mais do que a capacitação de estudantes das camadas populares para prestarem o vestibular, uma formação crítica imprescindível na vida universitária. Nossa chegada neste coletivo 
ocorreu em tempos e por razões distintas. Antes de falarmos das demandas profissionais e militantes que demarcaram nossa trajetória no Cursinho da Psicologia, faz-se necessário retomarmos nossas histórias familiares, que, como as histórias de muitas famílias negras, estão relacionadas ao acesso (ou negação) à educação.

Eu, Milena Natividade da Cruz, considero que a educação e até mesmo o espaço físico da escola foram determinantes na história da minha família, inclusive porque foi graças a esse campo que ela pôde ser constituída. Entre as décadas de 1968 e 1988, minha avó foi servente numa escola primária em Pinheiros e levava a minha mãe, ainda pequena, para brincar com giz e lousa entre um expediente e outro. Por conta desse estímulo precoce e da rigorosa insistência de suas tias para que ela estudasse, minha mãe criou gosto pelo ensino e na adolescência começou a trabalhar como auxiliar de professora na mesma escola onde trabalhava sua mãe. Com o magistério obtido no ensino médio, minha mãe assumiu uma sala de aula na mesma escola e alcançou a condição de professora - tal da "filha da empregada", como diziam os diretores, agora pertencia ao corpo docente. Para aumentar sua especialização, decidiu fazer faculdade de História na PUC-SP, mas teve que interromper os estudos quando ficou grávida de mim a mais velha dos três irmãos. Ela só regressou à faculdade quando teve a oportunidade de se graduar em Pedagogia na USP. Hoje ela é supervisora de ensino e alcançar esse cargo foi a consolidação de que a educação foi definitivamente o lugar que propiciou a ela e aos meus irmão oportunidades para ascender socialmente, transformando a trajetória de gerações 
da nossa família. Outro ambiente escolar, que remonta mais à formação do meu pai, foi a escola de samba Vai Vai. Local onde meus pais se conheceram e cujo espaço de socialização permitiu parte da trajetória educacional do meu pai - sendo harmonia e administrando a escola durante os ensaios técnicos. Ele não pôde terminar o ensino básico, mas isso não o impediu de ser "mestre" na construção civil, com um apurado senso estético para arquitetura - meu Vilanovas Artigas particular.

Talvez tenha sido por essa combinação de formações familiares que eu tenha escolhido o curso de História (com ênfase nas artes visuais) como primeira graduação. Talvez seja uma jeito inconsciente de dar continuidade ao anseio investigativo e histórico de minha mãe, ou ainda vingar a falta de oportunidade de meu pai em se tornar artista-arquiteto. Ingressei na FFLCH-USP em 2012, e, desde o começo da graduação meu interesse de pesquisa estava voltado para o estudo de história das artes, com destaque para a relação com a história da cartografia. Tais temas começaram a tomar contorno da esfera da educação quando tive minha primeira experiência profissional no Cursinho da Psico.

Em março de 2015, ingressei na disciplina C.R.I.S.E. (Coletivo de Reflexão e Intervenção sobre o Espaço) na condição de palestrante convidada, pois na época começara a participar da Ocupação Preta, movimento universitário composto por estudantes negros que reivindicava as cotas raciais na USP, pressionando a universidade através de intervenções em sala de aula universitária, manifestações públicas no Conselho Universitário, e também por aulas públicas em escolas e cursinhos pré-vestibular sobre a importância dessa política pública. Por 
entender desde o começo da graduação que a educação seria meu campo de atuação política e ação social, essa última ação direta da Ocupação foi a que me levou a conhecer o Cursinho da Psicologia. Quanto à disciplina em questão, trataremos mais à frente, dada a importância dela nas nossas tentativas de criação de uma prática comprometida com o ensino democrático sobre crítica social, capaz de proporcionar uma formação docente que incluísse a justiça social nas preocupações pedagógicas, e que experimentasse estratégias educacionais para desenvolvimento de identidade racial na comunidade pedagógica. No ano seguinte, fui contratada para integrar a área de História. Durante 2016 lecionava duas disciplinas e só me desliguei do projeto em 2017, quando já tinha deixado o C.R.I.S.E. no começo do mesmo ano.

Eu, Louise Marinho, entendo que as minhas escolhas acadêmicas e profissionais também se relacionam com as experiências vividas e compartilhadas por minha família - por parte materna e paterna. Ambas as famílias foram demarcadas pela migração do Nordeste brasileiro para os bairros periféricos que estavam se formando em São Paulo no começo da década de 1960. Cresci ouvindo histórias de minhas avós, dos seus esforços para que seus filhos pudessem frequentar as poucas escolas que tinham perto de seus bairros. Cresci ouvindo relatos de como para uma de minhas tias a experiência de ir à escola era algo terrível e que minha avó deveria literalmente arrastá-la para sala de aula (essa mesma tia que teve uma trajetória no ensino regular demarcada pela negação de sua identidade positivada, também foi impedida anos mais tarde - quando pôde acessar o ensino superior - de se 
formar no curso de História da Universidade Federal do Paraná por discriminações racistas explícitas). Minha mãe era o seu porto seguro para as confissões e compartilhamento necessários para que ela pudesse criar resistências durante todo esse processo, muito porque também minha mãe pôde se formar no ensino regular com magistério. Para ela, era essencial garantir que suas irmãs e suas filhas tivessem o ensino regular garantido conjuntamente com a inserção no mundo do trabalho. Ela sempre sublinhou a necessidade de trabaIharmos e estudarmos.

Já a influência do meu pai está diretamente relacionada à escolha da minha formação acadêmica. Não lhe foi possível terminar o ensino regular, mas desejou durante toda sua vida ser professor de história e geografia. Ele que, durante minha infância, me instigou a estudar os conteúdos históricos que aprendia na escola e que, durante minha adolescência, pelo seu afastamento forçado devido às suas condições psíquicas, garantiram que eu seguisse a vontade trilhada por ele, tendo a certeza de que isso me traria um equilíbrio de memória familiar e anseios pessoais.

Delimito que a minha entrada profissional no campo da educação aconteceu de duas formas. Primeiro no campo da educação não formal, pelos atendimentos escolares em Museus. Essas experiências aconteceram de forma fechada às questões que me tocavam, enquanto formanda em história e mulher negra. Conjuntamente a essa experiência que denomino como traumática, entrei em 2014 para o Programa de Ensino à Docência (PIBID), programa do Ministério da Educação destinado à inserção dos alunos de graduação no ensino público. 
Meu interesse em participar do programa aconteceu em duas vertentes correlatas. Primeiro, pela possibilidade de desenvolver trabalhos no ensino público e territorialmente localizado na zona leste de São Paulo - local onde desenvolvi toda minha trajetória familiar e educacional - segundo pela possibilidade de aproximação aos estudos pós-abissais ${ }^{1}$ que influenciaram grandemente meu desejo em entender e trabalhar com as multiculturalidades em sala de aula. Durante este período participei ativamente de grupos de estudos que envolviam estudos antropológicos, sociológicos e históricos que buscavam formas de se trabalhar com a diversidade, não como temática externa que beira a homogeneização dos "corpos diferentes", mas sim como algo necessário para que uma nova construção de saberes aconteça.

Apesar dos limites e críticas ao programa, essa foi a minha primeira experiência educacional que de fato vivenciei e construí com professores e alunos em sala de aula. O trabalho com crianças do ensino fundamental envolvendo as leis 10.639 / 11.645, o uso de mitologias indígenas e afro - brasileiras e a construção de um conhecimento histórico compartilhado por produção de imagens me mostraram que o ensino poderia ser mais do que minha experiência familiar e individual demarcou - tanto no ensino regular como no ensino superior. Foi também integrando este grupo que fui "apresentada" ao Cursinho da Psico. O professor da escola municipal onde eu aplicava as oficinas do PIBID atuou no cursinho durante cinco anos e me convidou para entrevista para o corpo docente de 2016.

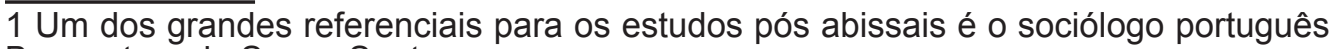
Boaventura de Souza Santos. 
Foi no Cursinho que aconteceu nossa aproximação enquanto amigas, historiadoras e, sobretudo, professoras preocupadas com uma educação que pautasse questões interseccionais de gênero, raça e classe. Apesar de compartilharmos a mesma trajetória por sermos estudantes do curso de história na Universidade de São Paulo, de nos olharmos e nos identificarmos, nós não nos relacionamos durante a graduação - provavelmente pela existência de uma espécie de "muro de vidro" nas pouco acolhedoras socializações acadêmicas. $O$ espaço compartilhado do Cursinho nos proporcionou um ambiente que potencializou as nossas necessidades de trocas de experiência, de convivência, de ação. Lá, pudemos, juntas, experimentar, criar e construir uma cumplicidade entre mulheres negras que somos. Essa cumplicidade chamamos de "manidades".

Consideramos importante frisar o uso desse jargão feminista. Acreditamos que o compartilhamento de nossas experiências, mesmo que individuais e restritas ao espaço onde atuamos, dialogam diretamente com os obstáculos comuns enfrentados pelo pensamento e o ativismo do feminismo negro, ou seja, a onipresença do racismo, do machismo e do classismo na sociedade brasileira. Isso não significa que as vivências dessas opressões se deram de forma homogênea para as duas. Não, cada uma percebeu as situações de acordo com suas especificidades. Entretanto, o compartilhamento dessas diferenças dentro da onipresença dessas desigualdades sociais nos proporcionou ter consciência e agir em conjunto; por isso optamos por registrar nossas memórias dentro do contexto de "manas". Primeiro porque, durante boa parte des- 
sa vivência, nós fomos as únicas professoras negras atuantes naquele espaço e, segundo, porque entendemos que nosso ativismo negro se perpetuou e se perpetua em nossas ações pedagógicas - estas que, por sua vez, sempre foram pensadas, discutidas e propagadas dentro da nossa comunhão. Esse compartilhamento das nossas diferenças dentro do nosso círculo de "manas" no Cursinho nos permitiu compor uma visão caleidoscópica sobre as situações que vivenciávamos: conforme o local onde batia a luz do evento vivido se produzia uma perspectiva de cor diferente, facetas prismáticas que se justapuseram no mosaico da experiência que tivemos ${ }^{2}$.

O próprio entendimento do nosso ativismo enquanto feministas negras aconteceu em um processo contínuo, compartilhado e fortalecido, mas igualmente pautado pela angústias de entendermos quais seriam nossas estratégias para a luta antirracista e antimachista, já que nossa contemporaneidade é marcada por figuras públicas (influenciadoras digitais, blogueiras e vlogueiras) que fazem das redes sociais o meio para a disseminação de seus projetos políticos. Talvez o entendimento da nossa identidade de professoras feministas negras tenha ocorrido, a princípio, por sabermos que não cabemos nesse contexto de ação (social/digital) $^{3}$, mas principalmente porque acreditamos 2 SARDENBERG, Cecilia M. B. Caleidoscópios de gênero: Gênero e interseccionalidades na dinâmica das relações sociais. P. 60. Disponível em: http://www.uel.br/revistas/uel/index.php/mediacoes/article/view/24125/Caleidosc\%C3\%B3pios\%20de\%20 g\% $3 \%$ AAnero

3 Temos conhecimento de que muitas mulheres negras que se tornaram figuras públicas por meio das mídias sociais desenvolvem trabalhos e ativismos que misturam as relações entre on-line e off-line. Não temos por prerrogativa avaliar e validar qual forma de ativismo é mais eficiente, mas sim demarcar que os espaços das mídias sociais 
que o nosso "modo de ser e ocupar o mundo"4 aconteceria, aconteceu e acontecerá no chão da sala de aula.

A persistência dessas certezas em nossos ativismos nos trouxe questões como: quais as possibilidades de equalizarmos nossas expectativas profissionais e militantes com as nossas memórias afetivas, que relacionavam diretamente nossas experimentações pedagógicas com a memória de nossas famílias? Famílias estas em que a educação, seu acesso ou o impedimento a ela, fundamentou sociabilidades e sonhos. Compartilhamos as coincidências de que nossas mães também são professoras negras e traçaram um caminho profissional que nos indica férteis possibilidades, mas também limites. Compartilhamos as coincidências de que nossos pais negros não puderam ter acesso à formação que desejavam, e buscamos em nossas atuações algo que se assemelha a uma reparação histórica daquilo que não Ihes foi possível ser. Quando falamos de "nós" estamos concomitantemente falando das memórias das famílias negras que têm caminhos parecidos. Reconhecemos isso em conversas com amigas e amigos, em escutas dos dilemas que acompanham nossas alunas e alunos negros. Ao falarmos de nós, falamos também dessa rede. Ao reconhecermos isso, como compartilhamos tais imbricações de saberes com nossos interlocutores negros e não negros, já que sabemos que a produção de conhecimento legitimada é aquele que possui um olhar que se pretende distanciado?

não correspondem às nossas especificidades.

4 Expressão usada pelas antropólogas Laura Moutinho, Valéria Alves e Milena Mateuzi no artigo “'Quanto Mais Você Me Nega, Mais Eu Me Reafirmo': Visibilidade e Afetos na Cena Negra Periférica Paulistana". Disponível em: https://seer.ufs.br/index.php/tomo/ article/viewFile/5428/4451 
Nossos "eus" e o micro universo de experimentações: C.R.I.S.E. - bloco raça no Cursinho da Psico.

Durante o segundo semestre de 2016, compartilhamos esse mesmo chão de sala de aula, dentro da disciplina do C.R.I.S.E. Em termos de grade curricular nesse coletivo, a disciplina CRISE é seu grande diferencial, uma vez que permite extrapolar os conteúdos engessados previstos pelos vestibulares ao tratar de temas como Raça, Classe, Gênero, Sexualidade, Corpo, etc. e que possui uma configuração própria, por reunir professor de disciplinas variadas para ministrá-la ${ }^{5}$. Por conter características diferentes das outras disciplinas, o C.R.I.S.E. construiu afetos, sociabilidades e desafios ímpares à nossa formação.

Se no espaço do Cursinho da Psico pudemos experimentar a nossa existência no mundo como professoras feministas negras, no C.R.I.S.E. pudemos "ousar" nas experiências, muito por conta das relações interpessoais construídas pelo corpo docente , mas também por conta da preocupação em manter um diálogo interseccional, visando a promoção de uma sensibilidade cada vez mais necessária sobre a responsabilidade educacional na efetivação da justiça social ${ }^{6}$. Compreender e atuar segundo esses parâmetros exigiu de nós educadores a busca por outras metodologias que fugissem da tradição escolar a que alunos e professores estão acostumados.

Trazermos para a disciplina o debate dessas questões ao longo do período letivo foi essencial para rompermos a con-

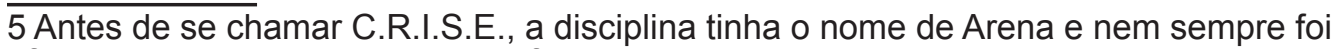
oferecida por um conjunto de professores. As mudanças acrescidas no programa da disciplina partiram da preocupação em não associar as discussões que eram promovidas ao clima de combate. Os professores que "refundaram" a disciplina eram majoritariamente da Geografia, por isso a "reflexão sobre o espaço" ser sublinhada.

6 Nossos depoimentos sobre o C.R.I.S.E. devem ser entendidos como registro que costura a rememoração dos acontecimentos vividos ao entendimento de como eles influenciaram e influenciam nossas escolhas pedagógicas e a nossa constante construção identitária. 
cepção de que a preparação para os vestibulares não deve conter uma reflexão sobre a sociedade onde os alunos estão inseridos e como o próprio processo do vestibular é uma das formas de remarcar as desigualdades estruturais estudadas. Talvez pela constância com que o C.R.I.S.E. trabalhou essas questões, essa mesma disciplina ficou demarcada como a responsável pela formação política dos educandos - minimizando a responsabilidade das outras disciplinas e educadores que compõem o Cursinho da Psico.

Ao final da nossa participação na disciplina, nossa percepção é de que o C.R.I.S.E. tem potencial para fornecer não apenas o conteúdo, mas os instrumentos de análise da condição social na qual estão inseridos os sujeitos. A disciplina é antes de mais nada um coletivo, que tem por importância uma construção conjunta e compartilhada do conhecimento, tanto entre o corpo docente quanto entre os alunos. O momento de planejamento de cada bloco temático proporcionava uma relação criativa entre os professores, em que tínhamos liberdade para criarmos nossas estratégias didáticas e escolhermos os conteúdos a serem trabalhados - realidade que não é possível dentro dos cursinhos pré-vestibular comerciais, que têm restrição limitante de tempo e de currículo.

Deve-se ressaltar que vivenciamos em temporalidades e modos diferentes os blocos de raça que aconteceram entre 2015 e 2017, o que nos possibilita analisar como o corpo docente como um todo se relacionou (ou não) com a temática que para nós era/é essencial: as identidades raciais no espaço educacional. 


\section{O desAFIO NA FORMAÇÃo de PROFESSORES: UMA COIN- CIDÊNCIA FORTUITA}

Como já citamos, a escrita deste "auto-estudo" surgiu de nossa necessidade de elaborar os processos ocorridos dentro do cursinho onde atuamos. Desde o começo das nossas caminhadas na militância sabemos que existe uma necessidade e urgência das mulheres negras em (re) escrever sobre si e suas histórias, alegrias e tristezas que as constituem, sendo esta escrita uma das formas mais impactantes de resistência, já que perpetua memórias. Podemos citar a importância desse direito para mulheres negras notáveis como Conceição Evaristo, Lélia Gonzalez e Beatriz Nascimento.

Para nós, a ligação entre escrevermos sobre nós e a autocrítica docente aconteceu após muitos eventos que nos desgastaram, que nos entristeceram e que não conseguíamos comunicar - ao menos não da forma como desejávamos em que não conseguíamos nos comunicar com nossos amigos e professores brancos. Uma das formas pelas quais começamos a entender a importância de compartilharmos nossas experiências ocorreu através da leitura de feministas como bell hooks, Angela Davis e outros autores que se debruçam sobre a questão da formação docente. Neste quesito, ao procurarmos referências no livro Justiça Social: desafio para a formação de professores deparamo-nos com o artigo de Jean Moule, professora universitária negra norte americana que viu na escrita autobiográfica formas de se pensar pedagogias antirracistas $^{7}$. Para ela, a escrita de uma auto-análise tem grandes

7 MOULE, Jean. "Justiça social na formação docente: fardo invisível para o professor de cor". In: PEREIRA, J. E. D.; ZEICHNER, K. M. (Orgs.). Justiça Social: desafio para 
potenciais de reflexão, pois "pesquisar a experiência vivida tem o poder de profundidade e entendimento, porque 'minhas próprias experiências de vida são imediatamente acessíveis a mim de uma maneira que as de nenhum outro são"'".

Assim, no artigo "Justiça social na formação docente: o fardo invisível do professor de cor", publicado pela teórica da educação Jean Moule, encontramos a referência teórica para elaborarmos e interpretarmos as nossas memórias nesse espaço. É importante dizer que esse movimento de rememoração e narrativa do processo vivido foi doloroso, por terem sido situações que nos afetaram e ainda ecoam constantemente em nós. A necessidade de uma referência teórica nos ajudou a criar um olhar mais distanciado, na escala de um estudo etnográfico.

Moule, analisa, na Universidade em que leciona, como a adoção da perspectiva da justiça social no programa universitário e na formação docente impactou a sua própria subjetividade. Ao se questionar se havia uma responsabilidade igualmente compartilhada entre os docentes para a implementação da Justiça Social nos programas das disciplinas e na formação proporcionada aos alunos, Moule faz um auto-estudo com base nas suas experiências e suposições que formulou ao fazer um balanço dos cinco anos em que se engajou na implementação do novo currículo.

A autora aponta que, para as professores negras universitárias, a mudança social é o principal norte de seus objetivos profissionais, mas que as estruturas burocráticas da faculdade, as relações interpessoais e o comprometimento de seus colegas as levam a ter uma sobrecarga de trabalho, frustra- 
ções e desgastes maiores se comparados com os docentes brancos. As percepções diferentes das desigualdades raciais levariam a comprometimentos e estratégias pedagógicas diferentes, portanto.

Partindo da Teoria do Desenvolvimento da Identidade Racial de Helms (1990), ou seja, "um sentido de grupo ou identidade coletiva, baseado na percepção de alguém que compartilha uma herança racial comum com um grupo racial em especial [...] a teoria do desenvolvimento da identidade racial se preocupa com a implicação psicológica da associação ao grupo racial"9, Moule cria, então, um esquema do Desenvolvimento da Interação Social sobre o processo de interação racial. O esquema é composto por quatro estágios:

1) "eu estou bem, você está bem": caracterizado como um "daltonismo social" que leva os indivíduos a não enxergar que raça é uma questão fundamental no debate para justiça social;

2) "alguma coisa não está bem": quando os indivíduos passam a refletir sobre sua identidade racial após um confronto alarmante - de natureza racista;

3) "eu estou bem, não tenho certeza quanto a você": combinação de diferentes estágios de desenvolvimento de identidade racial (como raiva, negação, pseudoconsciência, imersão, emersão). Às vezes se pode ter consciência da identidade racial e continuar perpetuando a opressão.

4) "eu estou bem, você está bem, nós estamos bem": percepção da importância de constante autocrítica e abertura para mais informações e modos de pensar, a existência de um trabalho integrado em prol da mudança.

9 lbid. P. 79. 
O estudo que Moule faz de si e seus colegas se apoia em tais estágios. Esse esquema nos pareceu uma organização instigante para o nosso caso, que, apesar da diferença entre o contexto racial norte-americano e o brasileiro, possui pontos de contato muito fortes com o estadunidense. Para dialogarmos com a metodologia e o esquema desenvolvidos por Moule, rememoramos algumas atividades e discussões das quais participamos desde a nossa entrada e que tiveram explícita relação com as questões raciais nos seus desdobramentos. Os blocos de raça no C.R.I.S.E. foram as primeiras situações que nos levaram a pensar a questão no coletivo, porém numa escala micro. Entretanto, certos eventos no ano de 2017 foram cruciais para compreendermos a dimensão dos obstáculos na escala macro - do coletivo como um todo.

\section{AutOESTUdO: REMEMORAÇÃO CRÍTICA DAS NOSSAS VIVÊNCIAS}

Quando eu, Milena, tive meu primeiro contato com o Cursinho da Psicologia, minha carga de trabalho era reduzida: participava apenas do planejamento e das aulas do C.R.I.S.E. uma vez por semana; não havia necessidade de estar em reuniões de gestão, fóruns, reuniões pedagógicas, entre outras atividades extra aula e meu vínculo com os demais professores do coletivo se restringia aos da disciplina.

Através dos debates com estes professores específicos, consegui aplicar os conhecimentos sobre o tema, sobretudo por eu ser ouvida e existir uma construção ativa das aulas, sobretudo quanto à composição do "texto da aula". Cada professor contribuía com os seus conhecimentos disciplinares sobre 
o tema (abordagem geográfica, antropológica, literária e histórica), mas a especificidade do grupo daquele ano foi a inclusão dos movimentos sociais como agentes da educação desde o começo do bloco - o convite para que integrantes da Ocupação estivessem na aula inaugural do tema, quando pude falar da necessidade das cotas raciais na USP e fui convidada para comparecer nas aulas seguintes sobre o tema. $O$ convite ocorreu também porque não havia professores negros na disciplina.

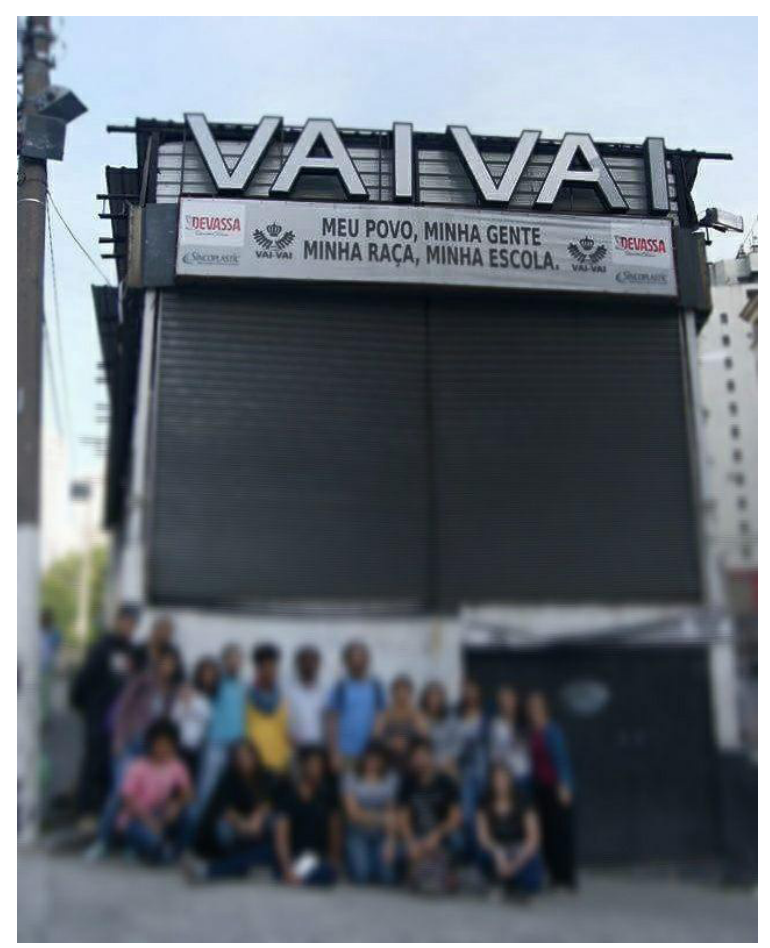

Saída de Campo "Nem tudo era italiano: a presença negra no bairro do Bexiga". Acervo pessoal.

As estratégias pedagógicas que utilizamos priorizavam sensibilizar os alunos mais através de dinâmicas em grupo do 
que pela discussão teórica e individual. Nesse sentido, as práticas teatrais do Teatro do Oprimido foram as principais. Guiada por um professor versado em tais práticas, as cenas que desenvolvemos com os alunos nos permitiram trabalhar com respostas para as opressões trazidas para o grupo naquelas encenações. Na ocasião, o espaço cênico permitiu-nos criar brechas na relação vertical (e por vezes inibidora) entre professores e alunos para podermos trabalhar com as representações dos traumas por racismo compartilhados pelos alunos com o grupo de professores.

As saídas de campo ampliaram para cidade o espaço de aprendizado que antes era confinado à sala de aula. Para abordarmos a construção da memória urbana em São Paulo, fizemos um mapeamento da história dos negros no bairro do Bexiga. O campo levou o nome de "Nem tudo era italiano: a presença dos negros no Bexiga"10 e poder construir essa atividade permitiu que eu incluísse na grade curricular saberes familiares sobre uma das escolas que me constituíram a escola de samba Vai Vai, propiciando assim um momento de alta carga emocional, especialmente para mim - algo que parece comum às docentes negras, como destaca Moule: "o custo psicológico para a pessoa de cor é alto porque recontar as histórias que ajudam os alunos a compreender uma trajetória diferente de vida faz com que ela reviva, parcialmente, essas experiências."11

10 A fundamentação do tema, bem como do nome da saída de campo foram retiradas do livro "Nem tudo era italiano: São Paulo e pobreza, 1890-1915" de Carlos José Ferreira dos Santos, 1998.

11 MOULE, Jean. "Justiça social na formação docente: fardo invisível para o professor de cor". P.87. 
A quantidade reduzida de aulas expositivas, embora mais dialogadas, permitiu que eu assuntasse pela primeira vez como elaboraria um "curso" acerca da temática racial. Assim, a cada aula, a cada demanda dos alunos, revisávamos o planejamento previsto. Entretanto, dada a inexistência de professores negros engajados naquele ano, minha visão sobre as questões raciais foi tomada como "palavra final", por ser a única presente - não houve negritudes em diálogo, portanto. A discussão sobre raça no Cursinho se iniciou no bloco, deu-se entre os professores da disciplina e os alunos e se encerrou na sua última aula. A questão racial não estava na agenda das preocupações pedagógicas do coletivo como um todo.

Em 2016, Louise e eu fomos contratadas pela área de História (eu na frente de História do Brasil e ela na frente de História Geral). Nossas interações se restringiam às tarefas da área até o momento em que pudemos participar do bloco de raça daquele ano.

Antes do período letivo, as professoras tomaram conhecimento da existência de relações abusivas, disparando a urgência em se discutir no Cursinho os relacionamentos sexuais e afetivos entre professores e alunas(os), tipo de relacionamento condenado pela nossa ética profissional, porém naturalizado em outros ambientes educacionais, principalmente no ambiente dos cursinhos pré-vestibular. Desde a explicitação dos casos de violência relatados pelas professoras, houve uma resistência dos professores em assumir suas responsabilidades na mudança do panorama que enfrentamos, como se o problema tivesse que ser conduzido pelas mulheres dali. A negação da co-responsabilidade fez com que as professoras 
procurássemos outras formas de tensionar tal parcela de responsabilidade negada pelos professores. Buscamos, assim, expressões artísticas que pudessem ecoar nossas vozes. Em certa medida, todas participaram de diversas maneiras nesse processo, dando-nos a sensação de acolhimento pela perspectiva de gênero.

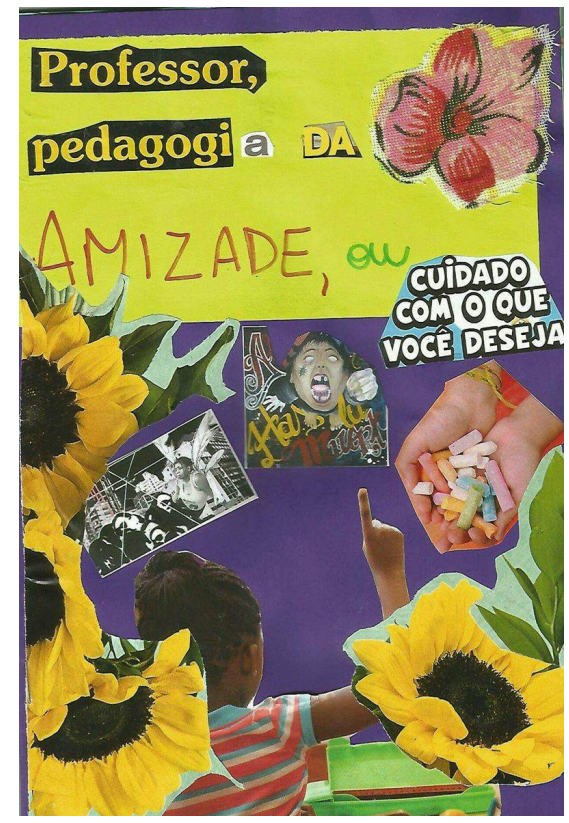

Capa do fanzine produzido pelas professoras do Cursinho da Psico sobre o problema das relações afetivo-sexuais na educação. 2016.

A formação de um grupo de estudos dos professores homens ocorreu após constante pressão das professoras e ação dos poucos professores que compreendiam a importância do tema. Foi nesse contexto, no qual os holofotes das discussões estavam voltados para as questões de gênero, que 
surgiu a necessidade de os professores discutirem as suas práticas pedagógicas com esse recorte, mas, ainda assim, o tratamento de Gênero foi restrito ao C.R.I.S.E. Por isso tal temática foi a primeira a ser trabalhada pelo grupo no primeiro bloco do ano. A partir da escolha dos alunos, seguiram-se os temas Corpo, Sexualidade, Classe e, no final do ano, a questão Racial - quando nós duas pudemos trabalhar juntas pela primeira vez.

No bloco de raça em 2016, era importante para os professores do C.R.I.S.E. do ano anterior revisarmos o planejamento de 2015. Ao procurar aumentar os momentos em que houvesse discussões teóricas mais aprofundadas, minha preocupação focalizava nuançar alguns pontos delicados que poderiam ferir a subjetividade das pessoas negras presentes na sala - no ano anterior, a quantidade de relatos de racismo sofrido pelos alunos, bem como a ênfase exclusiva no funcionamento da estrutura racista no Brasil por vezes deixava o ar da sala tenso e imobilizante. Entendia que esse tipo de tratamento nos eximiria da sensação de o C.R.I.S.E. ser uma "terapia em grupo" - algo que seríamos incapazes de executar dada a nossa formação e objetivo.

Tendo em vista essas questões e por ser o tema de encerramento do C.R.I.S.E. aquele ano, o planejamento do bloco sobre Raça se propôs a fazer uma revisão das temáticas dos blocos anteriores (Classe e Gênero), mas evidenciando como se deu a racialização delas no Brasil - cuja estrutura se assenta no passado colonial escravista e que, portanto, está visceralmente ligado ao racismo contra a população negra. Na primeira aula, a partir da análise de estudos demográficos sobre a cidade de 
São Paulo ${ }^{12}$ - território onde interagem os alunos -, introduzimos a necessidade de entendermos o processo histórico que levou a configuração da realidade atual observada.

\section{Cronograma bloco Raça - C.R.I.S.E. (2 semestre 2016)}

$1^{a}$ aula) Racializando o território: mapa da desigualdade racial em $S P$

$2^{\mathrm{a}}$ aula) Palestra "Ecos da escravidão negra na sociedade brasileira" com o prof. Luiz Felipe de Alencastro

$3^{a}$ aula) Racializando Classe - formação da sociedade de classe (racista) no Brasil.

$4^{\mathrm{a}}$ aula) Racializando Gênero - Feminismo Negro no Brasil

$5^{\mathrm{a}}$ aula) Afrofuturismo - obstáculos e horizontes para a juventude negra

Entrei no C.R.I.S.E. no último bloco de 2016, a convite da Milena para construirmos juntas o bloco racial. Meus desejos de entrada na disciplina se deram porque dentro do espaço do Cursinho sentia necessidade de falar sobre aquilo que me perpassava. Já possuía experiências em formação sobre a temática racial e de gênero voltada para jovens, mas gostaria de poder falar sobre isso no espaço em que até então me sentia acolhida. Acreditava que neste lugar, por não conter tão fortes as amarras institucionais encontradas no meio acadêmico, poderia potencializar as possíveis identificações entre a minha história e dos alunos e acreditava na possibilidade desse (re)conhecimento. Isso para mim é de suma importância, 12 Um dos materiais de apoio que utilizamos foi o relatório SP Diverso da Secretaria Municipal de Promoção da Igualdade Racial de São Paulo (SMPIR). Disponível em: http://www.prefeitura.sp.gov.br/cidade/secretarias/upload/igualdade_racial/arquivos/ Relatorio_Final_Virtual.pdf 
pois sou uma professora que se permite ser afetada dentro da construção de relacionamentos educacionais, o que acredito ser benéfico para a construção do saber.

Naquele ano mais uma vez enfrentamos o problema de fazer um planejamento de forma coletiva. Louise e eu assumimos a responsabilidade de cuidar dos conteúdos de cada aula, materiais de apoio, do contato com os convidados, da sistematização e compartilhamento das conversas após as aulas, da iniciativa de marcar as reuniões. A própria fala nas aulas se concentrou em nós, ainda que a discussão do racismo seja uma problemática branca ${ }^{13}$. Essa falta de disponibilidade não é um problema específico do bloco de raça, pois os professores da área geralmente trabalhavam com outras disciplinas também. Mas o fato dessa disponibilidade extra ser incorporadas por nós duas como um compromisso inquestionável acabou por nos demandar material, física e psicologicamente.

Entendemos que foi ao final desse bloco que o estágio "alguma coisa não está bem" aconteceu. Ao longo da construção do bloco, foi-se delineando a passividade na construção do bloco, pois a interlocução necessária para a formulação das atividades se deu mais entre nós professoras negras do que entre o grupo de um modo geral. De algum modo, a noção do conceito de fala estava deturpado nesse momento.

Consideramos que a irrupção desse estágio ocorreu com o caso da uma aluna negra que participou deste bloco e que

13 Durante a construção do bloco, pudemos acompanhar a vinda da artista Grada Kilomba na $32^{\mathrm{a}}$ Bienal de São Paulo. Suas reflexões sobre a luta antirracista podem ser ilustradas no artigo que fez para a revista Carta Capital - considerações que também utilizamos material de apoio aquele ano. Disponível em: https://www.cartacapital.com.br/politica/ 201co-racismo-e-uma-problematica-branca201d-uma-conversa-com-grada-kilomba 
vale a pena ser relatado com detalhes. Acreditamos que tal abalo (de impactos variados) no corpo docente do C.R.I.S.E. aconteceu por dois motivos complementares.

Primeiro, porque existiu uma tensão de negritudes dali. Por mais incisivas que fossem as suas falas, por ser uma muIher mais velha, frequentadora de muitos espaços culturais e econômicos, a aluna em questão não estava no mesmo patamar de formação identitária e política como as outras ali presentes. Foi um choque de negritudes, pois cada uma das pessoas negras ali presentes trouxe suas demandas para a discussão. Por conta dessa confrontação de lugares distintos que não dialogaram, questionamo-nos até que ponto o C.R.I.S.E. conseguiria abarcar as experiências desses alunos mais velhos, que trazem outros repertórios e formas de demonstrá-los? Essa é uma das questões que está posta até hoje para nós duas.

Segundo, porque houve um incômodo da própria aluna com a dinâmica do C.R.I.S.E. naquele bloco. Durante as aulas, a aluna discutia com outros colegas no corredor como os professores brancos quase nunca falavam. Uns alunos eram incisivos ao defenderem um entendimento de lugar de fala de que eles, brancos, não poderiam falar isso, porque nós, professoras negras, estávamos lá - concepção em parte corroborada pelo silêncio dos professores não negros. A aluna em questão pautava indiretamente a questão da responsabilização dos não negros.

Querendo ou não, de um jeito imperativo, ela trouxe um ponto que, contudo, era fundamental: o cuidado que devemos ter no uso dos materiais didáticos. Não percebemos que era uma dever do micro coletivo, mesmo tendo condições para 
traduzir um vídeo que estava em inglês, já que desejávamos nos comunicar dentro de um cursinho popular, lugar onde esse domínio linguístico jamais deveria ser uma barreira.

$\mathrm{Eu}$, Louise, me senti muito incomodada pelo modo como a crítica da aluna foi recebido, principalmente porque houve um movimento de diminuí-la, já que ela tinha sido a única aluna negra a questionar a forma em que o desenvolvimento do bloco ocorreu. Para nós, professoras negras, encararmos a crítica foi um processo lento e doloroso porque foi justamente nesse bloco que nossa comunhão foi gestada, principalmente na aula em questão, pois compartilhávamos frente aos alunos - e sem explicitar - nossas vivências familiares que nos construíram enquanto pessoas negras. Nessa aula pudemos de fato experienciar o que o movimento negro clama por "ancestralidade compartilhada", pensávamos que os alunos negros sentiriam o mesmo que sentíamos. Esse paradoxo de frustação pela forma como a crítica foi recebida (principalmente pelos professores brancos) e a certeza de que era possível construirmos juntos pela afetação dos nossos corpos e das nossas memórias fez com que eu continuasse no C.R.I.S.E. até para garantir que isso não se repetiria. Entretanto, meu momento de maior frustação veio no ano seguinte, pois não é possível construir de fato uma educação antiracista se os professores brancos não se sentem tocados e responsáveis pela discussão.

Iniciamos o ano letivo de 2017 com o "bloco raça", sendo uma demanda da avaliação coletivo do ano de 2016. Nesta avaliação, foi questionado o tempo de duração para essa questão (no ano anterior, o bloco raça foi o último) e foi ava- 
liado que este tema trouxera mais reflexões para o desenvolvimento do trabalho e do corpo docente. A atividade inicial para dispararmos o tema foi a "Caminhada dos privilégios"14. Durante a dinâmica percebi muitos comentários de alunos negros, principalmente alunas, se elas se encaixariam na identificação de negras ou morenas. Os alunos que demonstraram mais contundência à sua identidade racial demonstraram incômodos pelo "resultado" da dinâmica. Seus corpos haviam ficado para trás.

Na semana, a área de história - diferentemente dos outros anos, em que discutíamos a produção metodológica do conhecimento histórico -, optou por exibir o filme "O menino 23" seguido de um debate com o Professor Doutor Marcos Napolitano. Mais uma vez, o aluno que trouxe suas angústias durante a atividade do C.R.I.S.E. trouxe suas angústias à história narrada pelo filme, mesmo que o debate tenha focalizado a importância sobre a memória em situações traumáticas da história como foi a escravização da população negra africana durante trezentos anos e a ditadura civil militar. Talvez, tenha nos faltado dimensionar o impacto que o recebimento deste filme causaria nos alunos, que, por conta da linguagem melodramática, tocaria muito nas subjetividades dos alunos negros, já que a história de escravização narrada ali poderia ser a história de meus avós, dos avós deles, poderia ser a história da família de qualquer um e, naquele momento, estávamos construindo uma relação com os novos alunos. Não sabíamos as questões que os tocavam, não sabíamos de suas histórias. Sabíamos que a maioria se inscreveu no cursinho querendo alcançar o

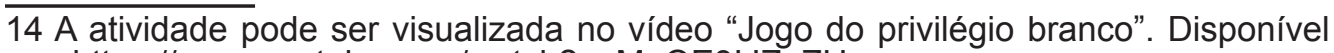
em: https://www.youtube.com/watch?v=MuOE3IJZoZU 
ensino superior. Mas os contextos que os levaram até ali, não. E naquela semana, talvez, esgarçamos subjetividades que não estavam prontas para serem compartilhadas, mesmo que pelo silêncio ou pela negação.

Na equipe de professores do C.R.I.S.E. de 2017, eu fui a única docente negra. $\mathrm{O}$ ano letivo teve início com as discussões sobre raça. O caminho pedagógico tirado em reunião de equipe foi:

Cronograma bloco Raça - C.R.I.S.E. (1º semestre 2017) $1^{\text {a }}$ aula) Quando falamos sobre Raça, falamos sobre o quê? $2^{\mathrm{a}}$ aula) Apropriação cultural

$3^{\mathrm{a}}$ aula) Racismo estrutural

$4^{a}$ aula) Feminismo Negro

$5^{\mathrm{a}}$ aula) Convidados dos Movimentos sociais.

De um modo geral, para mim, foi neste bloco, na sua construção e na sua aplicação, que alguns pontos da interação que vai do segundo ao terceiro estágio da interação racial se esgarçaram. Primeiro porque, apesar de um primeiro interesse demonstrado por todos os professores, não houve um esforço coletivo em entender a seriedade do que estava sendo proposto e que isso demandaria tempo, estudo e reflexão. Sempre ficou ao meu cargo pontuar que era necessário um maior estudo sobre o que são as relações raciais no Brasil, que para além de desigualdades estruturais existem construções subjetivas de negros, brancos e não brancos. Porém, as falas dos professores brancos pouco agregavam às subjetivadades, dos alunos e suas. Durante as aulas reiteravam 
constantemente a desigualdade acometida pela população negra. Entendo que a constatação dos processos de violações e desigualdades representam uma etapa importante às nossas preocupações pedagógicas, mas elas não devem se esgotar a este ponto, pois isto é reproduzir o lugar comum da denúncia das desigualdades e reproduzir este lugar é delimitar a nossa corporeidade à dor, à desesperança. É impossibilitar que os corpos negros se construam a partir de suas vontades, de seus desejos, de sua autonomia. Do contrário, é negar o direito que o corpo negro tem de se sentir enquanto corpo dotado de potência.

A angústia decorrente de como foi trabalhada a questão das violações foi exposta sobretudo quando um aluno negro mais velho verbalizou seu incômodo com as atividades teatrais propostas e a forma como o "conteúdo" foi passado - forma esta que só reforçou o lugar da exclusão que seu corpo negro vivenciou durante muitos anos. Ele sabe que sua masculinidade é constantemente renegada e objetificada, não pela leitura teórica sobre desigualdade, mas pela leitura que seu corpo encarna diariamente em ações discriminatórias. Esse saber, contudo, não foi considerado como vital no processo de diálogo pedagógico, foi tratado pelo corpo de professores brancos como um problema de socialização individual. Seu mundo foi ignorado.

Quando eu, professora negra, levei essas questões para o balanço do bloco, tive estas questões tratadas como meramente emocionais. Foi afirmado que não havia um problema racial ali, justamente porque estávamos nas aulas destinados a essa temática. Por ter sido tratada como "temática" externalizada é que os incômodos raciais surgiram nos sujeitos que não podem abrir mão de suas identidades racializadas. 
Foi a partir desses episódios ocorridos no C.R.I.S.E., aglutinados com conflitos que ocorreram no coletivo, que passei a questionar a identidade "popular" do Cursinho da Psico. Para nós duas, uma educação que se entenda "popular" é uma educação que considera as identidades raciais dos alunos e alunas e que rompa (ou ao menos problematize) com os privilégios da branquitude. Conseguir problematizar essas questões dentro do espaço educacional, fazendo com que os sujeitos brancos também sejam agentes desse questionamento, corresponde a uma ação efetiva e necessária para o rompimento dos cânones culturais eurocêntricos, tomados como patrimônios universais e universalizantes, que impedem e distorcem outras expressões e epistemologias culturais. Ao fazermos um recorte analítico racializado, questionamos a permanência da norma colonizadora - branca, masculina e heteronormativa. Este olhar interssecional tornou-se quase como nossa missão, que por ser pesada demais, transformou nossa convivência em fardo. Optei, assim como Milena, por sair do C.R.I.S.E.

\section{“EU ESTOU BEM, NÃO TENHO CERTEZA QUANTO A VOCÊ" NO MACRO UNIVERSO DO CURSINHO}

À luz das nossas experiências nesse micro universo que é o C.R.I.S.E., para encaminharmos nossas demandas para o Cursinho da Psico, foi preciso lançarmos um olhar retrospectivo sobre situações incômodas que tínhamos passado no coletivo desde então, impressões individuais que nós duas tínhamos, mas que até então não havíamos compartilhado uma com a outra. A troca de nossas impressões foi possível quando planejamos a Semana de Formação para os professores, ocorrida 
no início de 2017. A Semana de Formação nasceu da necessidade de reparo das tensões sobre as questões de gênero que eclodiram durante 2016, mas o destaque para o recorte racial só ocorreu quando nós entramos na comissão de organização.

É importante frisar as indisposições que cada uma de nós teve com um professor específico antes da Semana de Formação, incômodo que só foi compartilhado e tratado como um caso grave a ser enfrentado durante o preparo da Semana, quando soubemos do tratamento que ele despendeu a uma de nossas alunas (por coincidência mulher, negra e periférica):

O meu professor racista exemplar mal completou os 30 anos de idade e tem doutorado na USP. Ele goza de todas as características de um típico professor universitário uspiano (branco, classe média, hétero ou que se faz de) e, por conta de seus privilégios orgulhosamente afirmados, com frequência, infantiliza as professoras negras e outros professores que não eram do mesmo grupo social dele. Por se sentir num patamar (social, ético e até mesmo 'biológico') mais elevado que algum de seus colegas, esse professor se sentia autorizado a compartilhar com aqueles que julgava serem seus iguais (ou seja, brancos, estudantes de cursos disputados) falas misóginas e racistas quando não se valia desse discurso em tom jocoso na frente de todos os professores, que poucos e poucas vezes questionam tais falas; esse mesmo professor se sentiu autorizado, inclusive, a falar para uma aluna negra e periférica que ela não passaria no mesmo curso que o dele por ser 'muito difícil para ela'.

$15 \mathrm{Em}$ abril deste ano, foi lançada nas redes sociais a hashtag \#meuprofessorracista, em que estudantes negros relataram suas situações racistas vividas no ambiente escolar. Coincidentemente, na semana em que foi lançada, nós duas soubemos que mais posturas discriminatórias eram praticadas pelo professor em questão. 
Ao decidirmos que traríamos este caso como pano de fundo para as discussões raciais na Semana de Formação, entendíamos que assim estaríamos estabelecendo uma proposta de conscientização para a importância do tema e que a construção do diálogo entre o corpo docente seria consequência dessa provocação inicial.

Esta ação sinalizava a necessidade de ampliarmos os horizontes do coletivo acerca das discussões interseccionais. Entretanto, os eventos que se seguiram à Semana de Formação nos demonstraram como tal abordagem ainda é limitada no coletivo como um todo, apesar da ciência sobre as questões de gêneros. Pareceu-nos sintomático, por exemplo, a atividade voltada às mulheres no dia $8 \mathrm{M}$, que não conseguiu contemplar uma abordagem racial inclusiva, chegando a reproduzir estereótipos destinados aos corpos das mulheres negras (caso que mais uma vez destacou a importância de refletirmos o uso de materiais didáticos e a representação dos corpos negros). O discurso e a postura recorrentes do feminismo branco, principalmente suas ações discriminatórias foram apontadas, culpabilizaram a nós, professoras negras, pela inexistência de diálogo:

Assim, meus professores racistas não são meus professores de fato, mas se colocam nesse lugar e assim o fazem quando se acham no direito de me indicar leituras sobre bell hooks, mesmo quando eu já preparava uma aula especial sobre a autora que há tempos eu estudava; quando uma professora branca ficou perplexa ao perceber que eu conheço a obra pedagógica/feminista da bell hooks e ela não; quando acha- 
ram legítimo questionar a minha escolha musical, pois se julgavam mais informados e a par do que eu sobre a proposta estética de artistas negrxs que eu conheço há tempos; que falam de mutilação genital, mas para tanto afirmam estereótipos racistas sobre o continente africano. Enfim, menosprezando e ridicularizando os nossos conhecimentos, formações, experiências.

A fim de encontrarmos mediações ao conflito que se instaurou no coletivo após a denúncia que fizemos na "hashtag" \#meuprofessorracista, fomos atrás de referências que nos servissem, ao mesmo tempo, de alento, para prosseguirmos com o nosso objetivo de propor uma educação democrática em sala de aula, e de inspiração, para traçarmos ações que conscientizasse os docentes não negros para a urgência de pensar as práticas pedagógicas no seu prisma racial. A mudança do quadro tenso em que se encontra o coletivo atualmente deverá ter como norte o quarto estágio de que fala Moule, ou seja, "eu estou bem, você está bem, nós estamos bem" e não pode prescindir da discussão sobre a branquitude. Mas, para tanto, é fundamental que haja uma mobilização dos não negros do coletivo para refletirem e não perpetuarem nas relações profissionais, pessoais e nas concepções pedagógicas os privilégios que possuem.

Almejamos extrapolar os alcances do debate racial, do perímetro das relações de afeto interpessoais para a formação dos professores, que são nossas e nossos parceiros na luta pelo acesso à universidade e a uma educação que se queira mais justa ${ }^{16}$. A princípio, as apostas que fizemos e fa-

16 Quando aqui usamos o sentido de "justiça", falamos menos no sentido da justiça Jurídica e mais no sentido do sentimento gerado contra uma violação de poder. No caso, este nosso sentimento de "justiça" está diretamente relacionado com a transfor- 
remos para que a mudança positiva aconteça têm se voltado para os nossos principais interlocutores, as alunas e alunos.

\section{UM OLHAR OPOSITIVO SOBRE A MEMÓRIA}

Em nossos planejamentos e conversas com frequência nos deparamos com a difícil tarefa de falarmos sobre as possibilidades dos corpos negros que fujam ao peso dos estereótipos advindos em grande medida dos processos de escravização da população negra-africana, principalmente porque temos por enfoque um público que traz no corpo as chagas históricas desse processo desumanizador. Compartilhamos nessas conversas as potências que as imagens trazem para o ato de reconhecimento, da comunicação, das possibilidades de mudança. Assim, dentro dos nossos anseios pedagógicos desejamos elaborar uma abordagem da temática racial que ressaltasse outro tipo de representação visual de assuntos estanques para a população negra. Começamos a buscar timidamente imagens que nos conectavam, que nos mobilizavam, que nos afetavam e, passamos a contrapor essas sensações aos desafios pedagógicos que encontramos dentro do espaço do Cursinho.

O que começou com conversas despretensiosas, risos, choros e imaginação foi tomando forma de um projeto em que pudéssemos de fato experenciar um olhar transformador. $E$ foi na leitura da pensadora bell hooks que começamos a vislum-

mação social que desejamos, e que são inseparáveis das nossas identidades raciais, de gênero e de classe. Para nós, quando falamos de "justiça" e, de educação popular não há possibilidades se não considerarmos esses marcadores sociais. 
brar um caminho possível. A autora nos foi a inspiração motriz por pontuar em seus escritos como proporcionar a construção de uma nova comunidade pedagógica feminista interssecional e a pensar em outras linguagens que rompam com transferência de modelos figurativos que só reproduzem uma lógica colonizada de negritude. Em "O olhar opositivo", hooks busca contribuir para o debate sobre o olhar da mulher negra no cinema e como esta encara a representação de si nessa arte. Para a autora, o ato de olhar é uma ação política, um mecanismo de poder que é ambivalente, pois ao mesmo tempo em que é usado como meio de dominação (como o caso dos escravizados punidos por olharem seus senhores), também dá brechas para a emersão da resistência e agenciamento, quando há a criação do que chama de Olhar Opositivo:

"Diante do contexto da exploração de classe, e da dominação racista e machista, foi apenas por meio de resistência, luta, leitura e olhar 'a contrapelo' que as mulheres negras têm conseguido valorizar nosso processo de olhar o suficiente para o nomear publicamente [...]. E é claro que há o prazer extra [no ato de olhar] se, durante o processo de interrogação, encontra-se uma narrativa que convida a espectadora negra a envolver-se com o texto sem sofrer ameaças de violação." 17 .

Temos como objetivo instrumentalizarmos as imagens na construção de um material pedagogico para que seja possível

17 hooks, bell "O olhar opositivo - a espectadora negra". Disponível em: https://foradequadro.com/2017/05/26/o-olhar-opositivo-a-espectadora-negra-por-bell-hooks/\#more-675 
uma outra narrativa sobre os corpos negros, uma narrativa que valorize um futuro, conseguindo assim romper com a essencialização de que estes corpos são constituídos pelas violações. Existe um futuro múltiplo que deve ser tecido a partir das experiências e, principalmente, dos desejos desses sujeitos.

Tal é o olhar das moças da tela "Ever the Women Watchful" da artista Lynette Yiadom-Boakye ${ }^{18}$. O desenvolvimento desse olhar desafiador e contranarrativo tem nos levado a pensar como podemos nos valer dessa estratégia no campo da educação. Ao voltarmos olhares críticos para as nossas memórias, podemos transcender o lugar da dor e da culpa para vislumbrarmos um projeto que busque a transformação (nossa e dos nossos alunos) em sujeitos transformadores da realidade observada.

\section{REFERÊNCIAS BIBLIOGRÁFICAS}

hooks, Bell. "O olhar opositivo - a espectadora negra". Tradução publicada no site Fora de Quadro, 26 de maio 2017. Disponível em: https://foradequadro.com/2017/05/26/o-olhar-opositivo-a-espectadora-negra-por-bell-hooks/

MOUTINHO, Laura;ALVES, Valéria; MATEUZI, Milena."'Quanto Mais Você Me Nega, Mais Eu Me Reafirmo': Visibilidade e Afetos na Cena Negra Periférica Paulistana". Revista do Programa de Pós Graduação em Sociologia da Universidade Federal do Sergipe, 265-291, n.28 (2016). Data de acesso: 25 de setembro de 2017. Disponível em: https://seer.ufs.br/index. php/tomo/article/viewFile/5428/4451

18 A obra em questão é a imagem na primeira abre o nosso relato. "Ever the Women Watchful", Lynette Yiadom-Boakye. New Museum, 2017. 
MOULE, Jean. "Justiça social na formação docente: fardo invisível para o professor de cor” In: PEREIRA, J. E. D.; ZEICH

NER, K. M. (Orgs.). Justiça Social: desafio para a formação de professores. Belo Horizonte: Autêntica Editora, 2008.

"O racismo é uma problemática branca, diz Grada Kilomba". Entrevista feita por Djamila Ribeiro e publicada na revista Carta Capital, 30 de março 2016. Disponível em: https://www.cartacapital.com.br/politica/201 co-racismo-e-uma-problematica-branca201d-uma-conversa-com-grada-kilomba

SARDENBERG, Cecilia M. B. Caleidoscópios de gênero: Gênero e interseccionalidades na dinâmica das relações sociais. Mediações - Revista de Ciências Sociais, 56-96, v.20, n.2 (2015). Data de acesso: 4 de janeiro de 2016. Disponível em: http://www.uel.br/revistas/uel/index.php/ mediacoes/article/view/24125/Caleidosc\%C3\%B3pios\%20 de $\% 20 \mathrm{~g} \%$ C3\%AAnero

Submissão: 19/10/2017

Aceite: 20/10/2017 